\title{
Awareness about hepatitis B infection among the grass root level health and family planning workers in a selected health complex at Dhaka district
}

Rezaul Karim

From $16^{\text {th }}$ International Symposium on HIV and Emerging Infectious Diseases

Marseille, France. 24-26 March 2010

\section{Background}

Regarding their awareness about Hepatitis B infection.

\section{Methods}

This descriptive cross sectional study was carried out amongst 145 health and family planning workers of Tejgaon Thana complex. Mohakhali, Dhaka. The health workers were selected randomly and a structured questionnaire was used as research instrument. A score sheet was prepared to assess the level of awareness.

\section{Results}

The mean age of workers was 22.12 years with standard deviation of 4.2 years. Majority of them were H.S.C (39.60\%) and S.S.C (42.76\%) passed. Nine of them (6.21\%) were found graduates and two of them (1.38\%) were found post graduates. It was observed that $79.3 \%$ were married and remaining $19.31 \%$ were unmarried and $1.38 \%$ was widow. Majority of them were found Muslims 91.72\%). The mean length of service was 3.23 years with standard deviation of 2.25 years. More than four fifth $(86.21 \%)$ knew infected blood is the source of Hepatitis B infection followed by contaminated syringe and infected person. Regarding the mode of transmission majority opined infected blood transfusion (86.21\%), use of contaminated syringe (67.59\%) and sexual contact $(59.31 \%)$ were the principal way. But only few $(16.55 \%)$ opined about transplacental transmission. The highest percentage of high risk group was identified as close relatives $(78.62 \%)$, followed by professional

Correspondence: drr_karim@yahoo.com

Nipsom, Dhaka, Belarus blood donors (71.03\%), doctors (67.59\%), medical technologist (51.03\%), nurses (50.34\%), prostitutes (44.83\%) and dental surgeons. Majority were unaware (77.24\%) about complication of hepatitis B infection. It was found in this study that only $28.28 \%$ had tested their blood for HbsAg and only $8.27 \%$ took vaccine against. Hepatitis B. regarding knowledge on preventive measures against Hepatitis B, 91.03\% opined healthful environment sanitation, $70.34 \%$ vaccination, $63.45 \%$ use of disposable syringe, $63.45 \%$ washing hands after handling infected patient and only $31.72 \%$ safe sexual habit. Majority (70.94\%) opined the necessity of health education regarding lowering the incidence of hepatitis $B$ infection. $\mathrm{Bi}$-variate analysis revealed that younger age had poor awareness regarding Hepatitis B infection $(p>0.05)$. Similarly higher level of education had good awareness than lower level of education ( $p>0.05)$. However as per point score only $20 \%$ had shown good awareness and majority were found average $(46.9 \%)$ and poor awareness $(33.60 \%)$.

\section{Discussion}

Research finding concluded that level of education and good practice can prevent infectious disease.

Published: 11 May 2010

doi:10.1186/1742-4690-7-S1-P153

Cite this article as: Karim: Awareness about hepatitis B infection among the grass root level health and family planning workers in a selected health complex at Dhaka district. Retrovirology 2010 7(Suppl 1):P153. 